\title{
82. Chemical Composition of the Volatile Matters Emitted by the Eruptions of Miyake Island in 1962
}

\author{
By Kimio Noguchi, Seiichi Ueno, Hiroshi Kamiya, \\ and Toshio NishiIdo \\ Department of Chemistry, Faculty of Science, \\ Tokyo Metropolitan University \\ (Comm. by Yuji ShibatA, M.J.A., June 12, 1963)
}

At about $200 \mathrm{~km}$ SSW of Tokyo, lies a small volcanic island, Miyake, circular in shape and $8 \mathrm{~km}$ in diameter, composed of basaltic rocks. At the centre part of the island, rises the peak of Mt. Oyama about $700 \mathrm{~m}$ above sea level. A great eruption occurred in 1940. Since then, the mountain was in a dormant state until the 23rd of August, 1962. At 20:58 of the 24th of August, 1962, a strong earthquake occurred on the island, and about $22: 20$ of the same day an eruption started at the midslope of Mt. Oyama and continued until early morning of the 26th. Matsuda and Morimoto, ${ }^{1)}$ geologists, made a precise report of the eruption of Miyake Island in 1962.

The present authors visited Miyake Island on the 10th of December, 1962 and collected volatile matters from new lavas and new cinder cone, Sanshichiyama, created by the eruption in 1962.

Methods of Investigations. (1) The authors used mercury maximum thermometer and a thermocouple of alomel-chromel type for the measurement of the temperatures of lavas and fumaroles. (2) The gases collected by using vacuum tubes of $300 \mathrm{cc}$ at the field, were analyzed by gas-chromatographic method. (3) The condensed waters which were collected by leading fumarolic gases into hard glass tubes of 1 inch diameter which were cooled with air.

Analytical Procedures. (1) $\mathrm{pH}$-values were determined by colorimetric method. (2) Chlorine ion contents of condensed waters were determined by Mohr's method, after the samples were neutralized with nitric acid or sodium hydroxide solution. (3) $\mathrm{SO}_{4}^{2-}$ contents were determined by weighing the precipitates of barium sulphate, after the samples were acidified with hydrochloric acid, and to these barium chloride solution was added. (4) Determination of $\mathrm{NH}_{4}^{+}$. The condensed waters were added with hypobromous salt to decompose ammonium ion. The amounts of the excess of hypobromous salt were determined by titration with thiosulphate, after the solutions were added with potassium iodide and acidified with hydrochloric acid. On the other hand, $\mathrm{NH}_{4}^{+}$contents were colorimetrically determined by photometer,

1) T. Matsuda and R. Morimoto, Kagaku, 32, 578-585 (1962). 
after the solutions were suitably diluted with distilled water and added with Rochelle salt and Nessler's reagent. The results obtained by these two methods coincide with each other. (5) Fluorine contents were determined by titrating the condensed waters with $0.1 \mathrm{~N}$ thorium nitrate solution, using sodium alizarin-sulphonate as an indicator, after the condensed waters were added with $\mathrm{pH} 3$ buffer solution. In this case, the aluminium contents were negligible and $\mathrm{SO}_{4}^{2-}$ contents were also small, when the condensed water was suitably diluted with distilled water. (6) C. O.D. The samples of condensed water were made alkaline with potassium hydroxide solution, added with $0.01 \mathrm{~N} \mathrm{KMnO}_{4}$ solution, heated on water baths for 30 minutes, and after that, the solutions were made acidic with sulphuric acid and added with $0.01 \mathrm{~N}$ succinic acid. The amount of the excess of succinic acid were determined by titration with $0.01 \mathrm{~N} \mathrm{KMnO}_{4}$ solution. The amount of permanganate consumed by the sample was calculated as oxygen.

Results. The locations where the samples were collected, are indicated in Fig. 1 and the analyses of condensed waters in Table I.

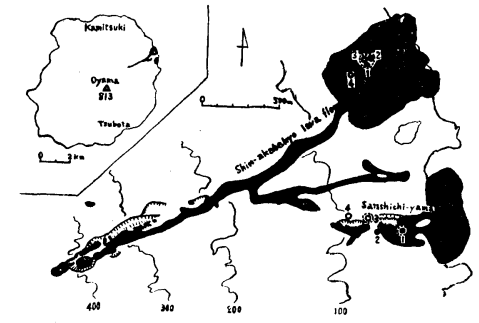

Fig. 1. Miyake Island and new vents and lava flows created on Aug. 24th, 1962.

- Fumaroles where acid condensed water was obtained.

- Fumaroles alkaline or newtral condensed water was obtained.

Fumaroles where sublimates were found.

This illustration was made by marking the positions of fumaroles on the original map by Matsuda and Morimoto.

Table I. Chemical compositions of the condensates from the fumaroles of lavas and Sanshichi-yama

\begin{tabular}{l|c|c|c|c|r|r|r|r}
\hline & $\begin{array}{c}\text { Temper- } \\
\text { ature } \\
\left({ }^{\circ} \mathrm{C}\right)\end{array}$ & $\mathrm{pH}$ & $\begin{array}{c}\mathrm{NH}_{4}^{+} \\
(\mathrm{mg} / \mathrm{l})\end{array}$ & $\begin{array}{c}\mathrm{Cl}^{-} \\
(\mathrm{mg} / \mathrm{l})\end{array}$ & $\begin{array}{c}\mathrm{F}^{-} \\
(\mathrm{mg} / \mathrm{l})\end{array}$ & $\begin{array}{c}\mathrm{SO}_{4}^{2-} \\
(\mathrm{mg} / \mathrm{l})\end{array}$ & $\begin{array}{c}\mathrm{Si}^{*} \\
(\mathrm{mg} / \mathrm{l})\end{array}$ & $\begin{array}{c}\mathrm{COD} \\
(\mathrm{mg} / \mathrm{l})\end{array}$ \\
\hline Lava flow No. 1 & & 6.5 & 548 & 325 & 190 & 408 & 11 & 21.8 \\
Lava flow No. 1 & 254 & 6.8 & 544 & 302 & 148 & 364 & 5 & 18.4 \\
Lava flow No. 2 & & 8.4 & 3540 & 2600 & 1320 & 1531 & 48 & 72 \\
Lava flow No. 2 & 249 & 8.1 & 2680 & 1700 & 900 & 1873 & 54 & 34.4 \\
Lava flow No. 3 & 235 & 1.9 & 130 & 555 & 515 & 17.5 & 105 & 0.5 \\
Lava flow No. 4 & 292 & 2.0 & 119 & 508 & 245 & 0.2 & 46 & 0.1 \\
Sanshichi-yama No. 1 & 189 & 8.8 & 1360 & 165 & 90 & 2165 & 5 & 22.8 \\
Sanshichi-yama No. 1 & 125 & 7.2 & 1955 & 840 & & 3650 & & 63 \\
Sanshichi-yama No. 2 & 125 & 7.7 & 365 & 400 & & 184 & 6 & 11.2 \\
Sanshichi-yama No. 3 & 220 & 2.0 & 1675 & 3770 & 70 & 0.7 & 10 & 1.2 \\
Sanshichi-yama No. 3 & 216 & 1.7 & 587 & 2220 & 61 & 0.5 & & 0.5 \\
Sanshichi-yama No. 4 & 243 & 2.1 & 124 & 534 & 87 & 5.0 & 9 & 1.8 \\
Sanshichi-yama No. 4 & 218 & 2.1 & 77 & 400 & 35 & 0.7 & & 1.3 \\
Oyama & 71 & 4.7 & 0.1 & 1 & 0 & 3.0 & 0 & 0.7 \\
\hline
\end{tabular}

* Silicon determined by molybdenum blue method. 
The temperatures of the fumaroles of the lava flows were $235-292^{\circ} \mathrm{C}$ and higher than those of the fumaroles of cinder cone, Sanshichiyama.

The chemical compositions of the gases, exclusive of the condensates of the fumarolic gases, are shown in Table II. The gases are remarkably contaminated with air. Carbon dioxide, carbon monoxide and methane are detected in a small amount. Oxygen contents of the gases are clearly lower than that of air. These facts will be easily understood by the explanation that $\mathrm{CO}_{2}, \mathrm{CO}$, and $\mathrm{CH}_{4}$ were generated by the thermal decomposition of the woods buried under the hot lava-flows.

Table II. Chemical composition of the gases, exclusive of condensates, from lava flows

\begin{tabular}{c|c|c}
\hline & $\begin{array}{c}\text { December } 13, \\
1962\end{array}$ & $\begin{array}{c}\text { December } 14, \\
1962\end{array}$ \\
\hline $\mathrm{N}_{2}$ & 81.9 vol. $\%$ & 81.5 vol. $\%$ \\
$\mathrm{O}_{2}$ & 16.1 & 10.5 \\
$\mathrm{CO}_{2}$ & 1.70 & 7.46 \\
$\mathrm{CO}$ & 0.19 & 0.31 \\
$\mathrm{CH}_{4}$ & 0.17 & 0.26 \\
\hline Total & 100.06 & 100.03 \\
\hline
\end{tabular}

As easily seen in Table I, according to $\mathrm{pH}$-value, all condensed waters are classified into two groups, strongly acidic and neutral or alkaline. The acidic waters are characterized by a poor content of sulphuric acid and C.O.D., while alkaline or neutral waters by a very high content of these components.

In a graph in which $\mathrm{Cl}^{-}$content is taken as ordinate and $\mathrm{NH}_{4}^{-}$ content as abscissa, the relation shown in Fig. 2 is obtained. The points for acidic waters are arranged almost on a line, indicating their composition to be $\mathrm{NH}_{4} \mathrm{Cl}$ or slightly deviated from this line to the side of higher chlorine content, while neutral or alkaline waters are remarkably deviated from ammonium chloride line to the side of higher ammonia content.

As for chlorine and fluorine contents, it is clear that two linear relationships indicated with I and II, exist between chlorine and fluorine contents as shown in Fig. 3. It may be supposed that the gases from Sanshichiyama would be at a later stage of volatile matters from magma than those from lava-flows, so far as chlorine and fluorine are concerned.

As for silicon and fluorine contents, the points for acidic waters are arranged almost on a line corresponding to the composition of hydrofluoric acid as shown in Fig. 4, while alkaline waters are remarkably rich in fluorine. These results may be well explained as follows: 
If volatile matters containing fluorine and silicon in the form of $\mathrm{H}_{2} \mathrm{SiF}_{6}$ meet with the substances which were produced by the thermal decomposition of woods, silicofluoric acid would be decomposed with water vapor from woods, according to the following reaction:

$$
\mathrm{H}_{2} \mathrm{SiF}_{6}+3 \mathrm{H}_{2} \mathrm{O}=\mathrm{H}_{2} \mathrm{SiO}_{3}+6 \mathrm{HF} \text {; }
$$

In such case, silicic acid will be deposited, so that the silicon content of gaseous substances will decrease, fluorine content of gases being unchanged.

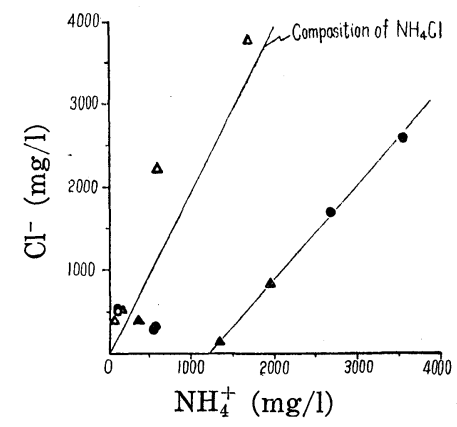

Fig. 2

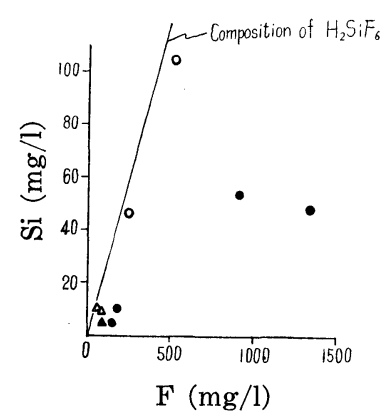

Fig. 4

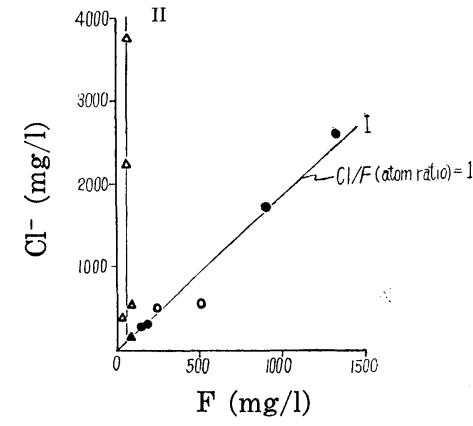

Fig. 3

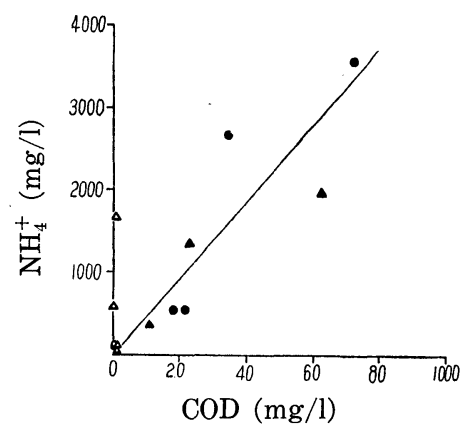

Fig. 5

Figs. 2-5. Relations between $\mathrm{Cl}^{-}$and $\mathrm{NH}_{4}^{+}$contents, $\mathrm{Cl}^{-}$and $\mathrm{F}$ contents, Si and $\mathrm{F}$ contents, and $\mathrm{NH}_{4}^{+}$and $\mathrm{COD}$ contents.

O Lava flow (acid condensed water)

- Lava flow (alkaline neutral condensed water)

$\triangle$ Sanshichi-yama (acid condensed water)

- Sanshichi-yama (alkaline neutral condensed water)

As for $\mathrm{NH}_{4}^{+}$and C.O.D. contents of the alkaline condensed waters, a linear relationship exists between these components as shown in Fig. 5. If both ammonia and organic substances are derived from the woods which were buried under the hot lava-flows, it is reasonable that such a relationship holds between these components.

The ultraviolet absorption curves of the alkaline condensed waters are shown in Fig. 6. The maximum value of optical density of the alkaline or neutral condensed waters exists at around $225 \mathrm{~m} \mu$. It is 
important to note that the maximum values of optical density of diethylamine and triethylamine are at $215 \mathrm{~m} \mu$ and that of quinoline at $220 \mathrm{~m} \mu$. These are organic compounds containing nitrogen. Between the maximum value of optical density and C.O.D. there exists a linear relationship as shown in Fig. 7 .

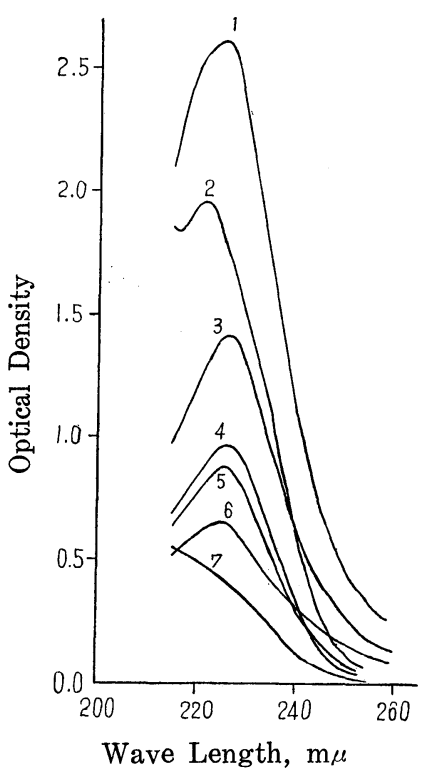

Fig. 6
Fig. 6. Ultra-violet absorption curves of alkaline or neutral condensed waters.

(1) Lava flow No. 2. (2) Sanshichiyama No. 1. (3) Lava flow No. 2. (4) Lava flow No. 1. (5) Lava flow No. 1. (6) Sanshichi-yama No. 2. (7) Sanshichiyama No. 1.

Fig. 7. Correlation between ultra-violet absorption and COD in alkaline or neutral condensed waters.

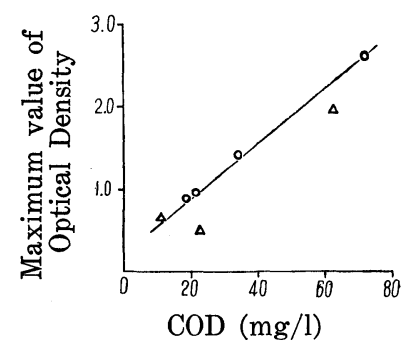

Fig. 7

A large part of sulphuric acid contained in neutral or alkaline condensed waters was formed probably by oxidation due to air from sulphur dioxide which was contained in the volatile matters from magma.

Sublimates. When the authors visited Miyake Island on December 10th, 1962, a large amount of white sublimates were found at the orifice of fumaroles. At that time white ammonium chloride crystals quickly accumulated on the cold part of a small wooden rod which was inserted into the orifice of a fumarole.

Table III. Chemical composition of the sublimates from lavas and Sanshichi-yama

\begin{tabular}{l|c|c|c|c|c|c|c}
\hline & Color & $\begin{array}{c}\mathrm{pH} \text { of 2\% } \\
\text { solution }\end{array}$ & $\begin{array}{c}\mathrm{NH}_{4}^{-} \\
(\%)\end{array}$ & $\begin{array}{c}\mathrm{Cl}^{-} \\
(\%)\end{array}$ & $\begin{array}{c}\mathrm{SO}_{4}^{2-} \\
(\%)\end{array}$ & $\begin{array}{c}\text { Insoluble } \\
\text { residue } \\
(\%)\end{array}$ & $\begin{array}{c}\text { Total } \\
(\%)\end{array}$ \\
\hline Sanshichi-yama No. 3 & White & 4.8 & 33.8 & 66.4 & 0.0 & 0.0 & 99.7 \\
Lava flow No. 1 & White & 3.5 & 32.8 & 65.3 & 0.5 & 0.0 & 98.6 \\
Lava flow No. 2 & White & 3.8 & 32.8 & 65.3 & 0.8 & 0.0 & 98.9 \\
Lava flow No. 2 & Brown & 3.6 & 32.1 & 63.1 & 2.6 & 0.0 & 97.8 \\
$\begin{array}{l}\text { Theoretical value of } \\
\mathrm{NH}_{4} \mathrm{Cl}\end{array}$ & & 33.3 & 66.7 & & & \\
\hline
\end{tabular}


The analyses of these sublimates are shown in Table III. White sublimates are almost pure ammonium chloride, while brownish white sublimates are crude ammonium chloride containing a small amount of sulphate.

As shown in Fig. 8, it is confirmed from X-ray diffraction pattern that the sulphate contained in sublimates is in the form of ammonium sulphate.

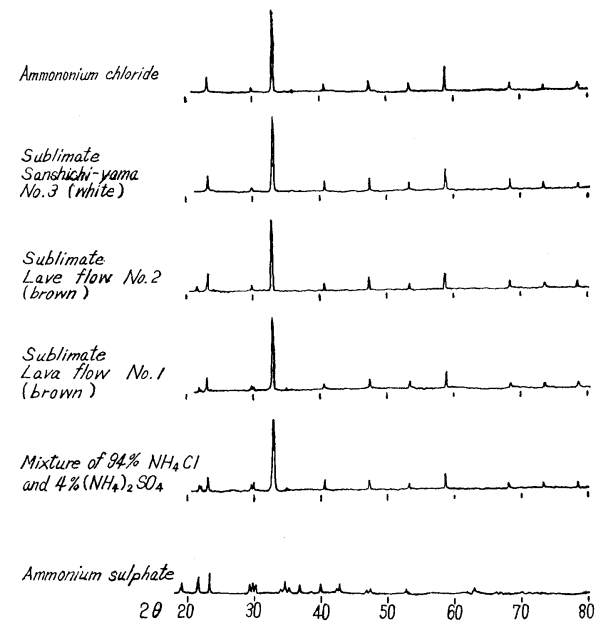

Fig. 8. X-Ray diffraction pattern of sublimates.

Conclusion. (1) The temperatures of the fumaroles of the lavaflows were $235-292^{\circ} \mathrm{C}$ and those of Sanshichiyama $125-243^{\circ} \mathrm{C}$. According to $\mathrm{pH}$-values, all condensed waters are classified into two groups, strongly acidic and neutral or alkaline. (3) Neutral or alkaline condensed waters are rich in ammonia and organic substances formed by the thermal decomposition of the woods which were buried under the hot lavas. (4) Two linear relationships, I and II, exist between chlorine and fluorine contents. It may be supposed that the gases from Sanshichi-yama belong to a later stage of evolution of volatile matters from magma than the gases from lava flows so far as chlorine and fluorine are concerned. (5) White sublimates are almost pure ammonium chloride, while brownish white sublimates are crude ammonium chloride containing a small amount of ammonium sulphate.

Acknowledgment. Acknowledgment is given to T. Kataoka, superintendent, and the staff members of the Miyake Administration Building, for their help.

This work was made possible by the science promoting funds given by the Ministry of Education of the Japanese Government. 